\title{
Fatalities from road traffic accidents among the young in Bahrain
}

R.R. Hamadeh ${ }^{7}$ and N.M.A. Ali ${ }^{2}$

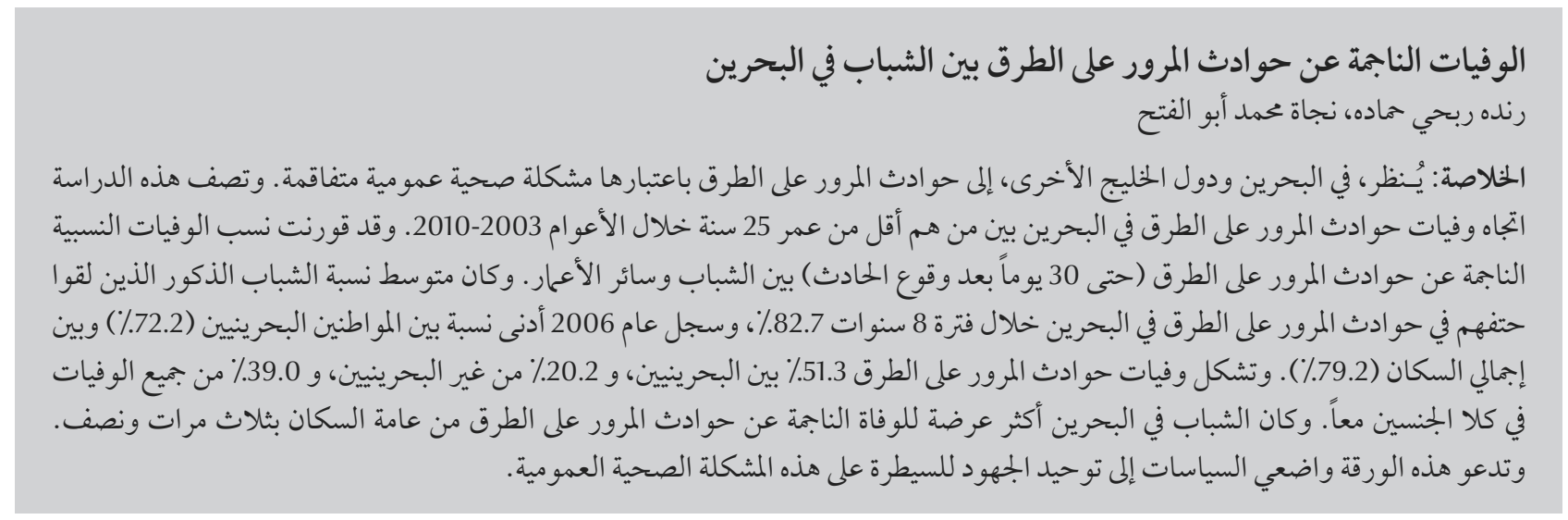

ABSTRACT In Bahrain and other Gulf countries, road traffic accidents (RTA) are recognized as a growing public health problem. This study described the trend of fatalities from RTA in Bahrain among those aged $<25$ years from 2003-2010. The proportional mortality ratios of RTA deaths (up to 30 days from the accident) among the young were compared with those of all ages. The average proportion of young males killed by RTA in Bahrain during the 8-year period was $82.7 \%$, with 2006 marking the lowest proportion among Bahraini nationals $(72.2 \%)$ and the total population (79.2\%). RTA fatalities constituted 51.3\% among the Bahrainis, 20.2\% of non-Bahrainis and 39.0\% of all fatalities in both sexes combined. The young in Bahrain were 3.5 times more likely to die from RTA than the general population. This paper calls on policy-makers to consolidate efforts to control this public health problem.

\section{Décès par accident de la circulation chez les jeunes à Bahreïn}

RÉSUMÉ A Bahreïn et dans d'autres pays du Golfe, les accidents de la circulation sont reconnus comme étant un problème de santé publique croissant. L'étude décrit la tendance des décès imputables aux accidents de la circulation à Bahreïn chez les jeunes de moins de 25 ans entre 2003 et 2010. Le taux de mortalité proportionnelle due aux accidents de la circulation (jusqu'à 30 jours après l'accident) chez les jeunes a été comparé à celui de toutes les autres tranches d'âge. Le pourcentage moyen de jeunes de sexe masculin décédés par accident de la circulation à Bahreïn au cours de cette période de huit ans était de 82,7\%, 2006 étant l'année où les taux de décès chez les sujets Bahreïnis (72,2 \%) et dans la population totale (79,2 \%) étaient les plus faibles. Les décès imputables aux accidents de la circulation représentaient 51,3\% chez les Bahreïnis, 20,2 \% chez les non-Bahreïnis et 39,0 \% de tous les décès pour les deux sexes combinés. Les jeunes à Bahreïn avaient 3,5 fois plus de risque de décéder d'un accident de la circulation que la population générale. Cet article invite les responsables de l'élaboration des politiques à renforcer leurs efforts pour lutter contre ce problème de santé publique. 


\section{Introduction}

Road traffic injuries are a global public health problem and a neglected epidemic [1-3]. They caused over 1.3 million deaths worldwide in 2004, accounting for $2.2 \%$ of total deaths and $23.0 \%$ of total injuries. It is predicted that deaths from road traffic accidents (RTA) would become the 5th leading cause of death and the 3rd cause of disability-adjusted life years by 2030 after occupying the 9th rank in 2004 $[4,5]$. Road traffic injuries are the leading cause of death for those between 15-29 years and are consistently one of the top 3 causes of death for persons between 5-44 years $[6,7]$.

RTA tend to be under-recognized as a major health problem in developing countries $[1,3,7]$. The global status report on road safety showed that low and middle-income countries have higher average road traffic fatality rates (21.5 and 19.5 per 100000 population respectively) than high-income countries (10.3 per 100000$)$ [8]. In the Eastern Mediterranean Region (EMR) the incidence of RTA is 26.4 per 100000 versus 19.0 per 100000 worldwide [1]. RTA injuries are the leading cause of death for those between 15-24 years of age and the 2 nd cause among 5-14-year-olds in the Region [9]. In Bahrain and other Gulf Cooperation Council (GCC) countries, RTA are recognized as a growing public health problem [10-16]. The lifestyle of the people in Bahrain has changed remarkably during the last 30 years following the oil boom of the last century, with an enormous growth in the population, including an influx of expatriate workers. This has been accompanied by increases in the number of motor vehicles and expansion of the road networks $[17,18]$. Rising numbers of RTA and consequent increases in injuries and fatalities have accompanied these changes, thus making RTA mortality now the 8th highest cause of death in the country [Health
Information Directorate, personal communication]. Hence, the problem constitutes a major public health concern and a sizable burden on Bahrain's health care resources $[10,11]$.

In Bahrain, there is a national road safety strategy, with legislation that has included setting speed limits and regulations concerning drink-driving and the wearing of motorcycle helmets and car seat-belts (but not child restraints). However, the public's compliance with these laws is generally poor [5]. Road safety audits, national policies to promote public transportation and postcrash emergency care are available, but vehicle standards and national policies to promote walking and cycling are not $[5,9]$. Driving at high speed and while intoxicated are thought to be the main causes of RTA fatalities in Bahrain $[9,10]$.

Since young people under the age of 25 years constitute $35.0 \%$ of the total population of Bahrain, premature deaths from RTA in this age group are a major concern [17]. The study aimed to provide data for policy-makers about the burden of RTA mortality among this important age group to direct efforts to improve roadway traffic safety in Bahrain.

\section{Methods}

\section{Study design}

A retrospective review of the data compiled by the Bahrain Health Information Directorate on RTA deaths during the period 2003-10 was conducted.

\section{Sample}

RTA deaths included all traffic-related deaths that occurred within 30 days from the accident and were given a cause of death code using the International Classification of Diseases (version 10) codes V01-V99 and registered at the births and deaths registration office of the Public Health Directorate of the
Ministry of Health. The young were defined as all those aged $<25$ years. Annual population figures were based on the Central Information Organization published statistics for the study period [Central Information Organization, personal communication].

\section{Data analysis}

The data was entered and analysed using SPSS, version 19.0. The proportional mortality ratios (PMR) of RTA deaths among those aged $<25$ years compared with the PMR of all RTA deaths among all ages in Bahrain by sex and nationality were computed for the study period, in addition to average PMR and standard deviations. RTA deaths among the young by year, nationality and sex were also calculated as a proportion of all RTA deaths. Annual RTA fatality rates per 100000 population among the young by 5 -year age groups, sex and nationality were computed along with their respective $95 \%$ confidence intervals (CI). Furthermore, trend analyses were performed for the rates. Bahraini nationals and non-Bahrainis were analysed separately since the latter are transient, mostly from the Asian subcontinent, and may have different road-use patterns than the high-income Bahraini nationals.

\section{Results}

\section{Proportion of young people among RTA deaths}

The young comprised high proportions of the RTA deaths during the study period. Of all the RTA fatalities in Bahrain, the average percentage of those $<25$ years of age over the 8 -year period was 39.2\% (38.0\% in males, $42.2 \%$ in females) (Figure 1). The corresponding proportion for Bahraini nationals was 51.3\% (51.8\% and $49.7 \%$ for males and females respectively) and for non-Bahrainis was $20.2 \%$ (18.9\% and $36.5 \%$ for males and 
females respectively). The proportions of the young among all RTA fatalities were highest in 2006 and 2008 and lowest in 2004 and 2007. The trend among Bahraini nationals was similar to that in the total population, with peaks in 58.1\% in 2006 and 58.6\% in 2008 (Figure 1). Lower proportions were noted among the non-Bahraini nationals throughout the period (Figure 1).

The percentages of RTA deaths in young Bahraini females were generally high, peaking at $71.4 \%$ in 2009 , and exceeding those of their male counterparts in 2003, 2004 and 2009 (Figure 2).

Males comprised the majority of all the RTA fatalities among the young Bahrainis ( $82.1 \%)$, non-Bahrainis (86.0\%) and total population (82.7\%). The corresponding percentages for all ages were $82.4 \%, 91.4 \%$ and $85.3 \%$. The year 2006 marked the highest proportions of females killed by RTA among the Bahraini young (27.8\%) and all ages (27.4\%).

\section{Proportional mortality ratios among young people}

The average PMR of the RTA fatalities in Bahrain during the 8-year period among those aged $<25$ years was $13.5 \%$ (range: $9.8 \%-16.2 \%$ ) and among all ages was $3.9 \%$ (range: $3.5 \%-4.4 \%$ ) for the total population.

Table 1 shows how the PMRs of young people compared with the PMRs of the total population in each year, by sex and nationality, and the total (average) over the 8-year period. On average the mean proportion of young people killed by RTA was 3.5 (range: 2.7-4.3) times higher than all ages among the Bahrain population and 4.7 (range: 4.0-5.6) times higher among Bahraini nationals. In addition, Bahraini national young females had the highest average ratio (5.0) of RTA fatalities among the young to that of the total RTA deaths compared with all the other subgroups.

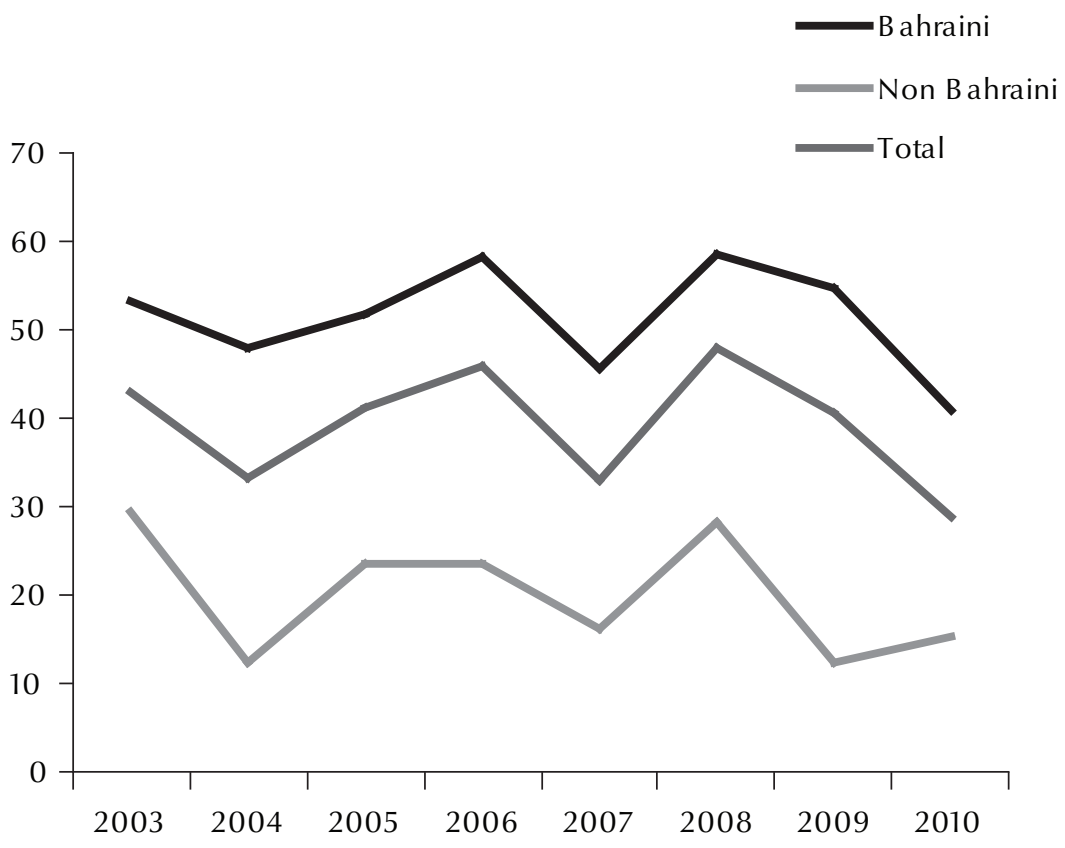

Figure 1 Road traffic accident deaths in Bahrain in those aged $<25$ years as a proportion of all ages in both sexes combined by nationality and year, 2003-2010

\section{Road traffic accident death rates among young people}

Table 2 shows that the highest RTA fatality rates among the whole population of young people in Bahrain were in 2006 and this was true for males (19.9/100 000), females
$(6.3 / 100000)$ and both sexes combined (13.4/100 000). As for Bahraini nationals, 2006 saw the highest RTA fatality rates among females and both sexes, while 2008 had the highest rate among males. The lowest death rates from RTA among the young in Bahrain

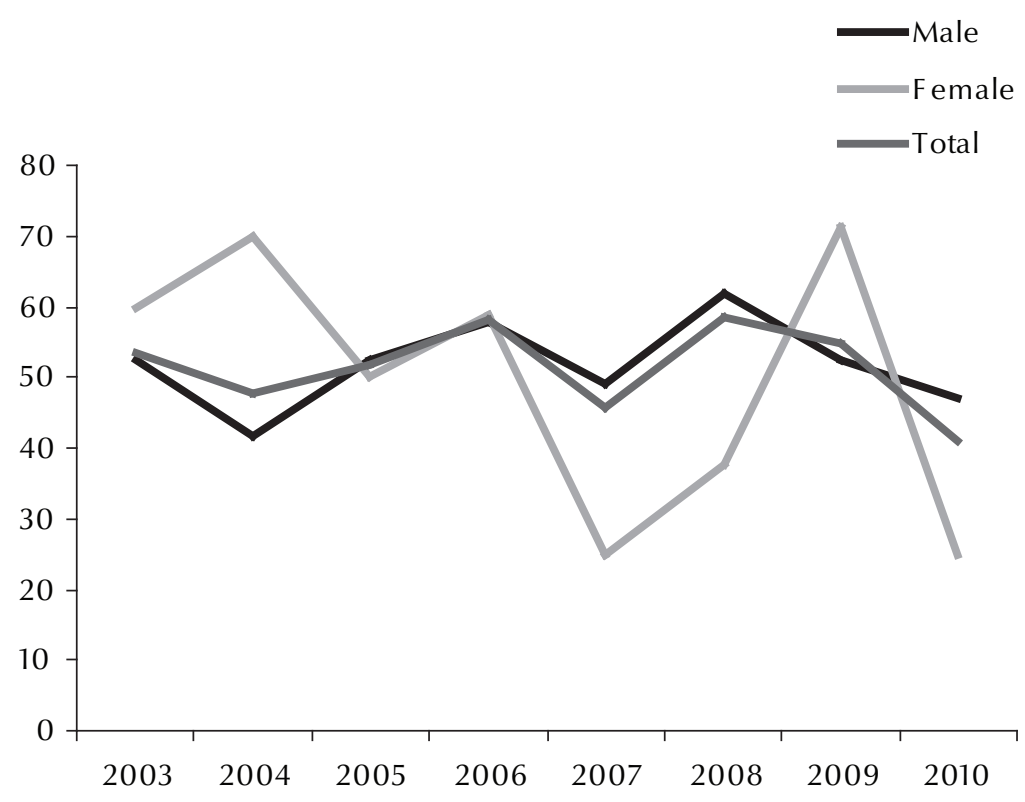

Figure 2 Road traffic accident deaths in those $<25$ years as a proportion of all ages among Bahraini nationals by sex and year, 2003-2010 


\begin{tabular}{|c|c|c|c|c|c|c|}
\hline \multirow[t]{2}{*}{ Year } & \multicolumn{2}{|c|}{ Males } & \multicolumn{2}{|c|}{ Females } & \multicolumn{2}{|c|}{ Total } \\
\hline & $<25$ years & All ages & $<25$ years & All ages & $<25$ years & All ages \\
\hline \multicolumn{7}{|l|}{ Bahraini } \\
\hline 2003 & 18.3 & 4.2 & 3.7 & 0.6 & 12.2 & 2.6 \\
\hline 2004 & 13.0 & 3.7 & 7.4 & 1.2 & 10.5 & 2.6 \\
\hline 2005 & 17.2 & 4.4 & 7.0 & 1.7 & 13.6 & 3.2 \\
\hline 2006 & 21.5 & 4.4 & 13.3 & 2.2 & 18.4 & 3.4 \\
\hline 2007 & 18.9 & 4.8 & 2.6 & 1.1 & 12.7 & 3.2 \\
\hline 2008 & 20.3 & 4.6 & 3.7 & 1.0 & 14.5 & 3.0 \\
\hline 2009 & 20.3 & 5.4 & 5.7 & 0.8 & 14.8 & 3.4 \\
\hline 2010 & 18.3 & 3.1 & 6.3 & 1.4 & 12.8 & 2.3 \\
\hline Total $^{\mathrm{a}}$ & $18.5(2.6)$ & $4.3(0.7)$ & $6.2(3.3)$ & $1.3(0.5)$ & $13.7(2.3)$ & $3.0(0.4)$ \\
\hline \multicolumn{7}{|c|}{ Non-Bahraini } \\
\hline 2003 & 27.0 & 10.4 & 50.0 & 18.2 & 21.7 & 9.0 \\
\hline 2004 & 13.3 & 9.9 & 0.0 & 24.8 & 7.1 & 7.7 \\
\hline 2005 & 20.0 & 12.6 & 50.0 & 22.6 & 13.1 & 8.2 \\
\hline 2006 & 25.8 & 11.0 & 0.0 & 23.6 & 10.7 & 6.6 \\
\hline 2007 & 15.0 & 13.0 & 33.3 & 27.0 & 9.0 & 8.7 \\
\hline 2008 & 25.8 & 10.0 & 100.0 & 29.5 & 13.2 & 6.6 \\
\hline 2009 & 10.3 & 10.5 & 33.3 & 18.2 & 6.7 & 6.4 \\
\hline 2010 & 14.3 & 9.0 & 25.0 & 21.7 & 22.0 & 7.9 \\
\hline Total $^{\mathrm{a}}$ & $19.0(6.7)$ & $10.8(1.4)$ & $36.5(32.1)$ & $23.2(4.0)$ & $12.9(6.0)$ & $7.6(1.0)$ \\
\hline \multicolumn{7}{|c|}{ All population } \\
\hline 2003 & 20.0 & 5.6 & 5.2 & 1.0 & 13.5 & 3.7 \\
\hline 2004 & 13.0 & 5.0 & 2.5 & 1.3 & 9.8 & 3.5 \\
\hline 2005 & 16.4 & 5.6 & 7.6 & 2.0 & 12.9 & 4.1 \\
\hline 2006 & 21.1 & 5.5 & 9.1 & 2.1 & 16.2 & 4.1 \\
\hline 2007 & 16.8 & 6.3 & 2.9 & 1.3 & 11.7 & 4.4 \\
\hline 2008 & 20.2 & 5.5 & 3.6 & 1.0 & 14.2 & 3.8 \\
\hline 2009 & 17.4 & 5.9 & 5.7 & 1.1 & 14.3 & 4.0 \\
\hline 2010 & 22.8 & 4.7 & 5.8 & 1.6 & 15.2 & 3.5 \\
\hline Total $^{\mathrm{a}}$ & $18.5(3.1)$ & $5.5(0.5)$ & $5.3(2.3)$ & $1.4(0.4)$ & $13.5(2.0)$ & $3.9(0.3)$ \\
\hline
\end{tabular}

${ }^{a}$ Mean (standard deviation).

were in 2010, in males and both sexes combined, among Bahraini nationals and the total population.

Further analyses by 5 -year age groups showed that the rates were higher in the 15-19 years and 20-24 years age groups compared with younger age groups (Figures 3 and 4). In both Bahraini national males and females, the rates were generally higher among those 20-24 years old throughout the 8-year period except for 2004 and 2006, when the death rates of the 15-19-year-olds were higher
(Figure 4). Lower rates were noted in children $<15$ years old in the Bahraini, non-Bahraini and total population in both sexes. Statistically significant trends were noted among non-Bahraini males $(P<0.029)$ and non-Bahraini males and females combined $(P<0.032)$.

\section{Discussion}

This study has described the trend of fatalities from RTA occurring in Bahrain. The available data on place of death for RTA fatalities in all ages indicates that $86.0 \%$ occurred in Bahrain during the study period [Health Information Directorate, personal communication]. However this does not imply that all the $14.0 \%$ dying abroad had their accidents outside the country as some would have had them in Bahrain and gone abroad for treatment. Moreover, there is no reason to believe that the proportions among the young would be different.

The finding that the RTA fatality rates in Bahrain were high among 


\begin{tabular}{|c|c|c|c|}
\hline \multirow[t]{2}{*}{ Year } & Male & Female & Total \\
\hline & Rate $/ 10^{5}(95 \% \mathrm{CI})$ & Rate $/ 10^{5}(95 \% \mathrm{Cl})$ & Rate $/ 10^{5}(95 \% \mathrm{Cl})$ \\
\hline \multicolumn{4}{|l|}{ Bahraini } \\
\hline 2003 & $16.9(9.7-24.2)$ & $2.5(0.0-5.4)$ & $9.9(5.9-9.9)$ \\
\hline 2004 & $11.8(5.8-17.8)$ & $5.8(1.5-10.1)$ & $8.9(5.2-12.6)$ \\
\hline 2005 & 17.8 (10.5-25.1) & $5.7(1.5-9.9)$ & $11.9(7.6-16.1)$ \\
\hline 2006 & $19.6(0.0-27.2)$ & $7.9(7.8-12.8)$ & $13.9(13.8-18.5)$ \\
\hline 2007 & $17.0(10.2-23.8)$ & $1.5(0.0-3.5)$ & $9.4(1.9-17.0)$ \\
\hline 2008 & $21.7(14.1-29.4)$ & $2.2(0.0-4.7)$ & $12.2(8.1-16.3)$ \\
\hline 2009 & $20.0(12.9-27.2)$ & $3.5(0.0-6.6)$ & $12.0(8.0-16.0)$ \\
\hline 2010 & $9.9(4.9-14.9)$ & $2.1(0.0-4.4)$ & $6.1(3.3-8.9)$ \\
\hline \multicolumn{4}{|c|}{ Non-Bahraini } \\
\hline 2003 & $22.6(6.9-38.3)$ & $6.9(0.0-16.5)$ & $15.6(5.9-25.2)$ \\
\hline 2004 & $11.0(0.2-21.8)$ & $0.0(0.0-0.0)$ & $6.1(0.1-12.0)$ \\
\hline 2005 & $16.0(3.2-28.9)$ & $6.6(0.0-15.6)$ & 11.8 (3.6-19.9) \\
\hline 2006 & $20.8(19.8-35.3)$ & $0.0(0.0-0.0)$ & $11.5(11.2-19.4)$ \\
\hline 2007 & $9.4(1.9-17.0)$ & $2.1(0.0-6.4)$ & $6.4(1.7-11.1)$ \\
\hline 2008 & $12.1(3.7-20.5)$ & $2.1(0.0-6.1)$ & $7.9(2.7-13.0)$ \\
\hline 2009 & $4.0(0.0-8.5)$ & $1.8(0.0-5.3)$ & $3.1(0.1-6.1)$ \\
\hline 2010 & $6.3(0.8-11.9)$ & $1.7(0.0-5.1)$ & $4.4(0.9-7.9)$ \\
\hline \multicolumn{4}{|c|}{ All population } \\
\hline 2003 & $18.2(11.6-24.8)$ & $3.4(0.4-6.4)$ & $11.1(7.4-14.8)$ \\
\hline 2004 & $11.6(6.4-16.9)$ & $2.0(0.0-4.2)$ & $8.3(5.1-11.5)$ \\
\hline 2005 & $17.4(11.1-23.7)$ & $5.8(2.0-9.7)$ & $11.8(8.1-15.6)$ \\
\hline 2006 & $19.9(19.7-26.6)$ & $6.3(6.3-10.3)$ & $13.4(13.3-17.4)$ \\
\hline 2007 & $14.6(9.4-19.9)$ & $1.7(0.0-3.5)$ & $8.6(5.6-11.5)$ \\
\hline 2008 & 18.7 (12.8-24.5) & $2.2(0.0-4.3)$ & $10.9(7.7-14.2)$ \\
\hline 2009 & $14.7(9.7-19.7)$ & $3.0(0.6-5.5)$ & $9.2(6.3-12.1)$ \\
\hline 2010 & 8.7 (4.9-12.5) & $2.0(0.0-3.9)$ & $5.6(3.3-7.8)$ \\
\hline
\end{tabular}

$C I=$ confidence interval.

the young is in accordance with data reported by other studies conducted in GCC countries [12-14]. Moreover, the young in Bahrain were on average 3.5 times more likely to die from RTA than the general population over the study period. The percentages of the young among RTA fatalities in Bahraini nationals $(51.3 \%)$ and in the total population (39.2\%) were higher than those reported globally (30.0\%) [6]. The lower percentages among the young non-Bahrainis can partly be explained by the fact that the majority in that age group were male labourers who could not afford to have private cars and mostly relied on the company's or public transport.
In Bahrain, the Ministry of Interior's statistics from 2010 showed that the majority of road users' fatalities were among drivers [Health Information Directorate, personal communication]. Qatar, a neighbouring country to Bahrain with a similar culture and population structure also reported that drivers constituted the majority of injuries and fatalities among road users aged $\leq 24$ years [6]. Thus, it can be assumed that most of the RTA fatalities among the young in our study in Bahrain were drivers as well.

The average proportion of males among RTA fatalities in the young (82.7\%) and all ages (85.3\%) in Bahrain were slightly higher than those reported for the EMR (80.0\%) [7]. Death rates from RTA among the young Bahraini and total population were about 6 times higher in males than females. Higher male RTA injuries and fatalities are associated with greater exposure to driving and higher risk-taking behaviours while driving $[9,19]$. Bahraini females are less likely to drive than their male counterparts. This could partly explain the higher PMR of RTA in females than male aged $<25$ years compared with all ages. However, the higher fatality rates among Bahraini females (7.9/100 000) and all females $(6.3 / 100000)$ in 2006 compared with the other years cannot 
Males

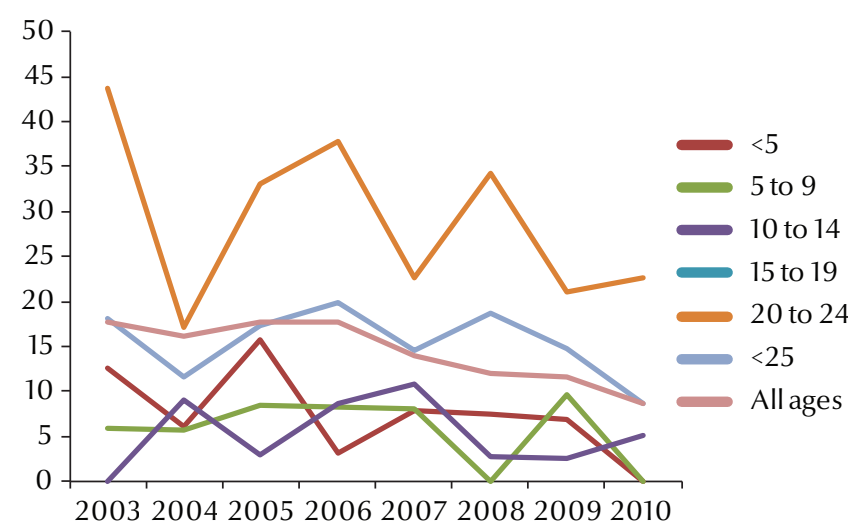

Females

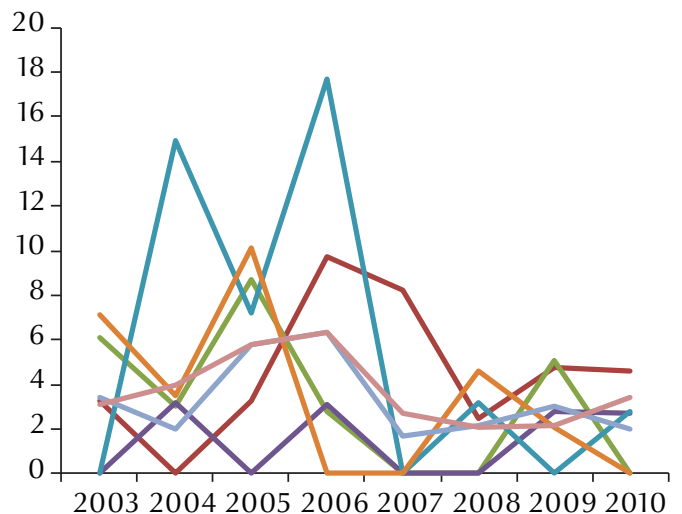

Figure 3 Road traffic accident death rates per 100000 population in Bahrain by sex and age group, 2003-2010

be explained. As for the declines in the RTA fatality rates in 2010, it is hoped that it is a reflection of a true decline that will continue.

A major limitation of this study is that it was based on the Ministry of Health's RTA mortality data that did not report the risk factors and circumstances of accidents. It has also been reported that the Ministry of Interior's road accident injury reporting has limitations as well [20]. Thus, the initial steps in the prevention and control of RTA in Bahrain should start by having a good surveillance system to improve the reporting of RTA mortality data and to identify risk factors.

The paucity of RTA-research studies urgently argues for future research on risk factors particularly road safety, and road users' characteristics including risktaking behaviours. Some drivers in affluent developing societies have dangerous behaviours and are not fully aware of the impact of these on safety $[14,21,22]$. For example, there is evidence that the national rate of seatbelt wearing is very low (only 22.0\%) [9] and there is widespread use of mobile phones while driving $[21,22]$. Educational programmes to raise the young's awareness about the impact of RTA injuries and fatalities on their vulnerable age, and their consequences on themselves, their families and the country should be introduced.

The study provides evidence for policy-makers that RTA among those aged $<25$ years in Bahrain is a major preventable public health problem. The socioeconomic burden of RTA fatalities among theyoung should urge policy-makers to direct more efforts towards roadway traffic safety to reduce the premature mortality in this important age group. The overall magnitude of the problem could not be assessed in this study, as it did not include the non-fatal consequences of RTA, which warrant equal attention. Nevertheless, the demand that those fatal and non-fatal injuries impose on the health sector, and their impact on the personal, family and community arenas, obliges the authorities to consider them as a public health priority area.

Competing interests: None declared.

Males

Age (years) Females
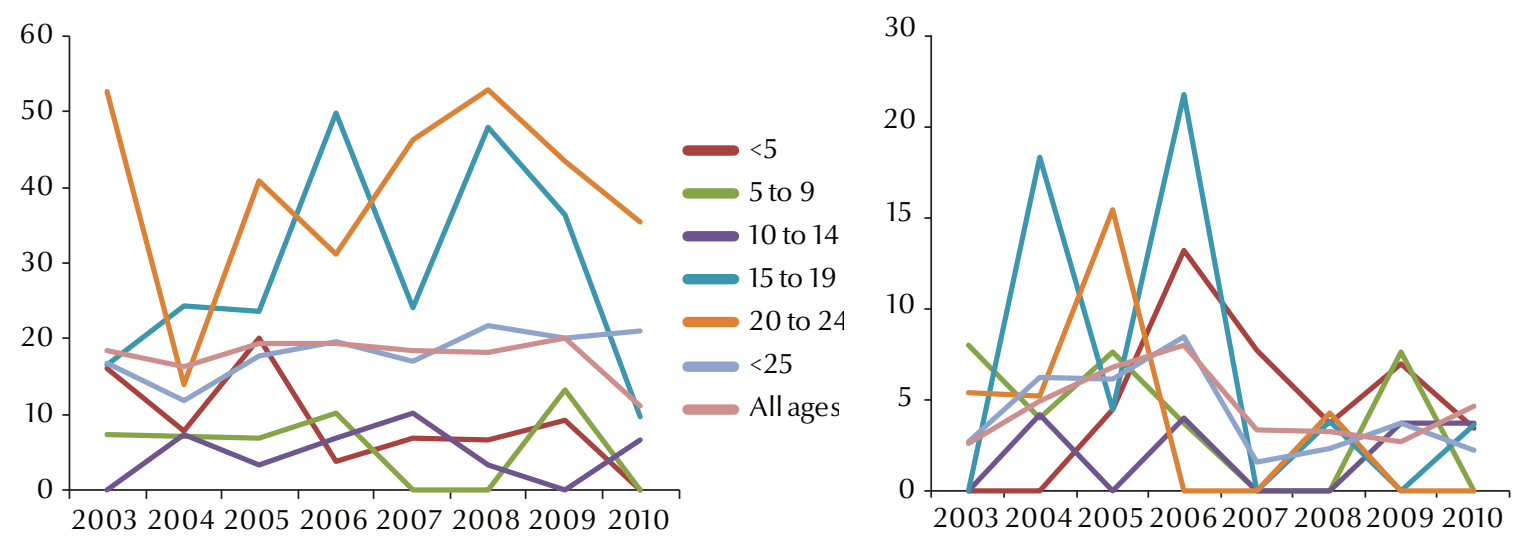

Figure 4 Road traffic accident death rates per 100000 population among Bahraini nationals by sex and age group, 2003-2010 


\section{References}

1. The global burden of disease: 2004 update. Geneva, World Health Organization, 2008.

2. Peden $M$, Hyder A. Road traffic injuries are a global public health problem. British Medical Journal, 2002, 324:1153-1154.

3. Nantulya VM, Reich MR. The neglected epidemic: road traffic injuries in developing countries. British Medical Journal, 2002, 324:1139-1141.

4. World health statistics 2008. Geneva, World Health Organization, 2008.

5. Future public health needs: commonalities and differences between high-and low-resource settings. Background paper 8. Geneva, World Health Organization, 2010.

6. Toroyan T, Peden M, eds. Youth and road safety. Geneva, World Health Organization, 2007.

7. Injuries and violence. The facts. Geneva, World Health Organization, 2010.

8. Global status report on road safety: time for action. Geneva, World Health Organization, 2009.

9. Eastern Mediterranean status report on road safety: call for action. Cairo, World Health Organization Regional Office for the Eastern Mediterranean, 2010.

10. Malki AA. Road traffic accidents, Bahrain 2001. Bahrain Medical Bulletin, 2002, 24:1-5.

11. Hamza AY, Al-Mousawi FR, Husel-Pincock A. Road traffic accidents in Bahrain. Bahrain Medical Bulletin, 2003, 25:105-110.

12. Bener A. The neglected epidemic: road traffic accidents in a developing country, State of Qatar. International Journal of Injury Control and Safety Promotion, 2005, 12:45-47.

13. Al Marzooqi AH, Badi M. Road traffic accidents in Dubai, 2002-2008. Asia-Pacific Journal of Public Health, 2010 22(3) (Suppl.):315-395
14. Bener A, Crundall D. Road traffic accidents in the United Arab Emirates compared to Western countries. Advances in Transportation Studies, 2005, 12(Section A 6):5-13.

15. Al-Shammari N, Bendak S, Al-Gadhi S. In-depth analysis of pedestrian crashes in Riyadh. Traffic Injury Prevention, 2009, 10:552-559.

16. Koushki PA, Bustan MA, Kartam N. Impact of safety belt use on road accident injury and injury type in Kuwait. Accident; Analysis and Prevention, 2003, 35:237-241.

17. Motorvehicles (per 1,000 people). The World Bank [online database] (http://data.worldbank.org/indicator/IS.VEH.NVEH.P3, accessed 21 July 2013).

18. Statistics. King Fahad Causeway Authority [website] (http:// www.kfca.com.sa/about_ass.htm, accessed 31 July 2013).

19. 19. Gender and road traffic injuries in the Eastern Mediterranean Region. World Health Organization Regional Office for the Eastern Mediterranean [online factsheet] (http://www.emro. who.int/vip/pdf/gender_road_traffic_injuries.pdf,

20. Al Mehza H. An evaluation of the "road accident injury report" system in the Kingdom of Bahrain: health system and policy implementations [MSc thesis]. Bahrain, Arabian Gulf University, 2007.

21. Lam LT. Distractions and the risk of car crash injury: the effect of drivers' age. Journal of Safety Research, 2002, 33:411-419.

22. Bener $\mathrm{A}$ et al. Mobile phone use while driving: a major public health problem in an Arabian society, State of Qatar-mobile phone use and the risk of motor vehicle crashes. Journal of Public Health, 2010, 18:123-129. 